\title{
Clinical observation on the treatment of acute liver failure by combined non-biological artificial liver
}

\author{
MAOQIN LI, JINGXI SUN, JIAQIONG LI, ZAIXIANG SHI, JIYUAN XU, BO LU, SHULI CHENG, \\ YANJUN XU, XIAOMENG WANG and XIANJIANG ZHANG
}

\begin{abstract}
Department of Intensive Care Unit, Xuzhou Central Hospital, The Affiliated Xuzhou Hospital of Medical College of Southeast University, Xuzhou Clinical School of Xuzhou Medical College of Nanjing University of Chinese Medicine, Xuzhou, Jiangsu 221009, P.R. China
\end{abstract}

Received May 10, 2016; Accepted September 2, 2016

DOI: $10.3892 / \mathrm{etm} .2016 .3887$

\begin{abstract}
The clinical efficacy and safety of different combinations of non-bio artificial liver in the treatment of acute liver failure was examined. A total of 61 cases were selected under blood purification treatment from the patients with severe acute liver failure admitted to the severe disease department of the hospital from December, 2010 to December, 2015. Three types of artificial liver combinations were observed, i.e., plasma exchange plus hemoperfusion plus continuous venovenous hemodiafiltration $(\mathrm{PE}+\mathrm{HP}+\mathrm{CVVHDF}), \mathrm{PE}+\mathrm{CVVHDF}$ and $\mathrm{HP}+\mathrm{CVVHDF}$. The heart rate (HR), mean arterial pressure (MAP), respiratory index $\left(\mathrm{PaO}_{2} / \mathrm{FiO}_{2}\right)$, liver and kidney function indicator, as well as platelet and coagulation function were compared. A comparison before and after the treatment using the three methods, showed improvement in the HRs, MAPs, $\mathrm{PaO}_{2} / \mathrm{FiO}_{2}$, total bilirubins (TBIL) and alanine aminotransferases (ALT) $(\mathrm{P}<0.05)$, of which TBIL and ALT were decreased more significantly $(\mathrm{P}<0.01)$ in the $\mathrm{PE}+\mathrm{CVVHDF}$ and $\mathrm{PE}+\mathrm{HP}+\mathrm{CVVHDF}$ groups. Only changes in the $\mathrm{PE}+\mathrm{HP}+\mathrm{CVVHDF}$ and PE+CVVHDF groups were statistically significant after prothrombin time and albumin treatment $(\mathrm{P}<0.05)$. The difference between the decrease in TBIL in the $\mathrm{PE}+\mathrm{HP}+\mathrm{CVVHDF}$ group and that in the HP+CVVHDF group was statistically significant $(\mathrm{P}<0.05)$. Treatment of the 61 patients using the artificial liver support system yielded a survival rate of $62.3 \%(38 / 61)$, and a viral survival rate of $35.0 \%$ (7/20); with the non-viral survival rate being $75.6 \%$ (31/41). In conclusion, following the treatment of three types of artificial livers, the function was improved to varying degrees,
\end{abstract}

Correspondence to: Dr Maoqin Li, Department of Intensive Care Unit, Xuzhou Central Hospital, The Affiliated Xuzhou Hospital of Medical College of Southeast University, Xuzhou Clinical School of Xuzhou Medical College of Nanjing University of Chinese Medicine, 199 Jiefang South Road, Xuzhou, Jiangsu 221009, P.R. China E-mail: limaoqinxi@126.com

Key words: acute liver failure, artificial liver, plasmapheresis, hemoperfusion, continuous veno - venous hemodiafiltration with the PE+HP+CVVHDF and the PE+CVVHDF method being better. By contrast, after the treatment of non-viral liver failure, the survival rate was significantly higher than the patients with viral liver failure.

\section{Introduction}

The severity of acute liver failure has high lethality (1). At present, there is no effective drug, and although liver transplantation is a very effective treatment, there is a lack of suitable donors. In addition, acute liver failure patients are in critical condition and the internal environment is in disorder; thus, patients cannot tolerate liver transplantation. Artificial liver support system (ALSS) takes the temporary and partial replacement of liver function, removes various harmful substances, and supplements the bioactive substances, to create a good environment for the patient's own cell regeneration and functional recovery and strive for valuable time (2-6).

Although a single model of non-biological artificial liver has a limited role, including blood or plasma perfusion, plasma exchange and continuous blood dialysis filtration, each treatment method's principle and function is different, each having its advantages and disadvantages, considering the patient's condition, and occasionally the combined application is also successful in achieving the purpose of treatment (7-9). Through a retrospective observation of plasma exchange combined with hemoperfusion and continuous hemodiafiltration ( $\mathrm{PE}+\mathrm{HP}+\mathrm{CVVHDF})$ and $\mathrm{PE}+\mathrm{CVVHDF}$ and $\mathrm{HP}+\mathrm{CVVHDF}$ treatment of acute liver failure, we observed the clinical efficacy and safety of three different combinations of non-biological artificial livers in the treatment of acute liver failure, to provide a clinical basis for the selection of effective and economical non-biological artificial liver treatment.

\section{Patients and methods}

General information. We observed 61 cases under blood purification treatment from patients with severe acute liver failure admitted to the Central Hospital of Xuzhou from December, 2010 to December, 2015, including 45 males and 16 females aged $40.1 \pm 15.6$ years (range, $20-82$ years). The score of the acute physiology and chronic health evaluation II 
(APACHE II) was $27.5 \pm 8.1$ points and the sequential organ failure evaluation score (SOFA score) was $13.49 \pm 2.93$ points. The patients with primary diseases included three cases with acute viral hepatitis, 17 cases with chronic toxic acute liver failure, 41 cases with non-viral induced liver injury (5 cases after cardiac surgery, 7 cases with drug poisoning, 13 cases after pregnancy and childbirth, 1 case with mushroom poisoning, 10 cases with severe infection and 5 other cases). The patients (PTA $\leq 30 \%$ ) belonged to the middle and advanced liver failure groups according to staging in the liver failure treatment guideline (6), including 48 cases with renal dysfunction, 35 cases with hepatic encephalopathy, 29 cases with gastrointestinal bleeding, 61 cases with blood clotting abnormalities and 31 cases with circulatory dysfunction.

The study was endorsed by Medical Ethics Standards and was approved by the Ethics Committee of the Central Hospital of Xuzhou. For all treatments, written informed consent was obtained from the patients or their families.

Treatmentmethod.In addition to the routine medical department and symptomatic support treatment, 61 patients were selected for $\mathrm{PE}+\mathrm{HP}+\mathrm{CVVHDF}$ or $\mathrm{PE}+\mathrm{CVVHDF}$ or $\mathrm{HP}+\mathrm{CVVHDF}$ artificial liver combination. In the $\mathrm{PE}+\mathrm{HP}+\mathrm{CVVHDF}$ group, the intubation tube was inserted through the femoral or jugular vein to establish a temporary path, the jugular vein was done firstly bedside and then Swiss Gambro PF2000N plasma separator was used. Subsequently, 2,000-3,000 $\mathrm{ml}$ of fresh plasma was exchanged every time, when the plasma was exchanged the flow rate was $80-120 \mathrm{ml} / \mathrm{min}$, the plasma separation rate was $25-30 \mathrm{ml} / \mathrm{min}$, the replacement time was $2.0-3.0 \mathrm{~h}$. After the completion of a single plasma exchange, the hemoperfusion was carried out again, the neutral macroporous resin (HA330-II type hemoperfusion cartridge, produced by Zhuhai Livzon Diagnostics, Inc., Zhuhai, China) was used. Once the perfusion apparatus adsorption capacity reached saturation, the perfusion apparatus was removed and the blood perfusion time was 2-3 h. After the single blood perfusion, CVVHDF treatment was carried out, the treatment time was $36.3 \pm 23.9 \mathrm{~h}$ (range of 10-51 h). In the PE+CVVHDF group, the procedure was identical to that mentioned above. However, after the plasma exchange the combined CVVHDF treatment was carried out. In the HP+CVVHDF group, according to the above method, after resin adsorption, the combined CVVHDF treatment was carried out. The 61 patients underwent a total of 171 treatments, including 25 cases under $\mathrm{PE}+\mathrm{HP}+\mathrm{CVVHDF}$ treatment, 87 cases under PE+CVVHDF treatment and 59 cases under HP+CVVHDF treatment (Table I).

Monitoring indicators. Before and after each treatment, the consciousness, heart rate (HR), mean arterial pressure (MAP), and arterial blood gas $\left(\mathrm{PH}, \mathrm{PaO}_{2}\right.$ and $\left.\mathrm{PaCO}_{2}\right)$, liver and kidney function indicators, blood routine examination, electrolytes and coagulation were detected.

Statistical analysis. Data were expressed as mean \pm standard deviation (SD), and the statistical analysis was carried out with SPSS 12.0 software (SPSS, Inc., Chicago, IL, USA). The comparison between the groups used one-way analysis of variance, and difference with $\mathrm{P}<0.05$ was considered to indicate a statistically significant difference.
Table I. Comparison between age, SOFA score, and treatment time between the three methods (mean $\pm \mathrm{SD}$ ).

\begin{tabular}{lccc}
\hline Groups & $\begin{array}{c}\text { Age } \\
\text { (years) }\end{array}$ & $\begin{array}{c}\text { SOFA } \\
\text { score }\end{array}$ & $\begin{array}{c}\text { CVVHDF } \\
\text { treatment } \\
\text { (hours) }\end{array}$ \\
\hline $\begin{array}{l}\text { HP+CVVHDF } \\
(n=59)\end{array}$ & $43.02 \pm 15.61$ & $12.56 \pm 2.89$ & $18.91 \pm 5.72$ \\
$\begin{array}{l}\text { PE+CVVHDF } \\
(n=87)\end{array}$ & $37.71 \pm 14.99$ & $13.85 \pm 3.44$ & $19.33 \pm 6.11$ \\
$\begin{array}{l}\text { PE+HP+CVVHDF } \\
(n=25)\end{array}$ & $39.22 \pm 17.63$ & $14.01 \pm 3.61$ & $20.08 \pm 5.03$ \\
& & & \\
\hline
\end{tabular}

\section{Results}

Comparison of the change in $H R, M A P$, respiration index and platelets before and after treatment in the three groups. As shown in Table II, before and after treatment in the three groups, the HR, MAP and respiratory index $\left(\mathrm{PaO}_{2} / \mathrm{FiO}_{2}\right)$ were significantly increased $(\mathrm{P}<0.05)$, and there was no significant difference in the platelet changes $(\mathrm{P}>0.05)$. In terms of the comparison between $\mathrm{PE}+\mathrm{HP}+\mathrm{CVVHDF}$ and $\mathrm{HP}+\mathrm{CVVHDF}$, the $\mathrm{HR}$ and $\mathrm{PaO}_{2} / \mathrm{FiO}_{2}$ changes varied significantly $(\mathrm{P}<0.05)$.

Comparison of coagulation function and liver function before and after treatment. As shown in Table III, a comparison among the three groups before and after the treatment showed that, the total bilirubin (TBIL) and alanine aminotransferase (ALT) were significantly decreased $(\mathrm{P}<0.05)$. Those in the $\mathrm{PE}+\mathrm{HP}+\mathrm{CVVHDF}$ and $\mathrm{PE}+\mathrm{CVVHDF}$ groups were decreased significantly $(\mathrm{P}<0.01)$, and the comparison between TBIL decrease in the PE+HP+CVVHDF group and that in the HP+CVVHDF group also showed a significant difference $(\mathrm{P}<0.05)$. Only changes in the $\mathrm{PE}+\mathrm{HP}+\mathrm{CVVHDF}$ and $\mathrm{PE}+\mathrm{CVVHDF}$ groups after the prothrombin time and albumin (ALB) treatment were statistically different $(\mathrm{P}<0.05)$.

Clinical results of the 61 patients in the group after ALSS treatment. At evaluation, 38 cases survived and 23 cases had died, with a mortality rate of $37.7 \%$ and a survival rate of $62.3 \%$. There were 7 viral cases surviving and 13 cases had died, with a mortality rate of $65.0 \%$ and a survival rate of $35.0 \%$. Furthermore, of the non-viral 31 cases survived and 10 cases had died, with a mortality rate of $24.4 \%$ and a survival rate of $75.6 \%$.

\section{Discussion}

Attention is given to acute liver failure due to poor prognosis arising from the rapid onset and rapid progression (10). Acute liver failure is essentially multi-organ dysfunction based on acute liver failure, and a poor simple supportive treatment effect, whereas the blood purification technology can effectively support multi-organ function of the patients while replacing the liver metabolism (11). In hepatic failure the artificial liver combination treatment is used, which plays a crucial role in reducing the patients' blood ammonia and 
Table II. Change comparison of the heart rate, mean arterial pressure, respiration index and platelet before and after treatment in the three groups (mean $\pm \mathrm{SD}$ ).

\begin{tabular}{|c|c|c|c|c|}
\hline Groups & $\mathrm{HR}$ & MAP & $\mathrm{PaO}_{2} / \mathrm{FiO}_{2}$ & PLT(x10/l) \\
\hline \multicolumn{5}{|c|}{ HP+CVVHDF $(n=59)$} \\
\hline Before treatment & $135 \pm 20.63$ & $81.02 \pm 14.97$ & $233 \pm 74.58$ & $77.28 \pm 43.74$ \\
\hline After treatment & $117 \pm 25.14^{\mathrm{a}}$ & $89.13 \pm 11.02^{\mathrm{a}}$ & $285 \pm 52.18^{\mathrm{a}}$ & $71.96 \pm 40.57$ \\
\hline \multicolumn{5}{|c|}{$\mathrm{PE}+\mathrm{CVVHDF}(\mathrm{n}=87)$} \\
\hline Before treatment & $137 \pm 21.27$ & $78.64 \pm 13.01$ & $219 \pm 70.57$ & $81.55 \pm 42.33$ \\
\hline After treatment & $115 \pm 23.94^{\mathrm{a}}$ & $88.39 \pm 11.86^{\mathrm{a}}$ & $294 \pm 55.93^{a}$ & $78.27 \pm 40.18$ \\
\hline \multicolumn{5}{|c|}{$\mathrm{PE}+\mathrm{HP}+\mathrm{CVVHDF}(\mathrm{n}=25)$} \\
\hline Before treatment & $141 \pm 22.87$ & $77.75 \pm 13.16$ & $201 \pm 66.91$ & $84.17 \pm 47.66$ \\
\hline After treatment & $108 \pm 23.11^{\mathrm{a}, \mathrm{b}}$ & $90.04 \pm 10.53^{\mathrm{a}}$ & $301 \pm 59.72^{a, b}$ & $78.11 \pm 43.65$ \\
\hline
\end{tabular}

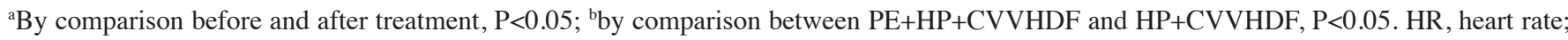
MAP, mean arterial pressure.

Table III. Comparison of coagulation function and liver function before and after treatment (mean \pm SD).

\begin{tabular}{|c|c|c|c|c|}
\hline Groups & PT (S) & $\mathrm{TBIL}(\mu \mathrm{mol} / \mathrm{l})$ & $\operatorname{ALT}(\mu / 1)$ & $\operatorname{ALB}(g / 1)$ \\
\hline \multicolumn{5}{|c|}{ HP+CVVHDF $(n=59)$} \\
\hline Before treatment & $25.41 \pm 12.22$ & $356.37 \pm 149.93$ & $392.14 \pm 256.63$ & $28.23 \pm 4.92$ \\
\hline After treatment & $21.88 \pm 11.57$ & $311.51 \pm 140.76^{\mathrm{a}}$ & $151.37 \pm 163.75^{\mathrm{c}}$ & $27.65 \pm 4.66$ \\
\hline \multicolumn{5}{|c|}{ PE+CVVHDF $(n=87)$} \\
\hline Before treatment & $26.05 \pm 16.02$ & $360.63 \pm 145.17$ & $353.72 \pm 279.58$ & $27.11 \pm 4.09$ \\
\hline After treatment & $20.13 \pm 10.66^{\mathrm{a}}$ & $269.55 \pm 131.88^{c}$ & $134.84 \pm 137.95^{\mathrm{c}}$ & $28.15 \pm 4.74^{\mathrm{a}}$ \\
\hline \multicolumn{5}{|c|}{$\mathrm{PE}+\mathrm{HP}+\mathrm{CVVHDF}(\mathrm{n}=25)$} \\
\hline Before treatment & $28.92 \pm 14.02$ & $379.58 \pm 155.02$ & $339.77 \pm 223.88$ & $27.02 \pm 4.51$ \\
\hline After treatment & $19.55 \pm 10.10^{\mathrm{c}}$ & $249.46 \pm 138.77^{\mathrm{cb}}$ & $136.07 \pm 131.33^{\mathrm{c}}$ & $29.21 \pm 4.73^{\mathrm{a}}$ \\
\hline
\end{tabular}

${ }^{\mathrm{a} B y}$ the comparison before and after the treatment $<0.05$; ${ }^{\mathrm{b}}$ by the comparison before and after the treatment $<0.01$; by the comparison between $\mathrm{PE}+\mathrm{HP}+\mathrm{CVVHDF}$ and $\mathrm{HP}+\mathrm{CVVHDF}, \mathrm{P}<0.05$. TBIL, total bilirubin; ALT, alanine aminotransferase; ALB, albumin.

serum bilirubin, removing or reducing the accumulation of toxic substances and improving the internal environment (12). The ALSS treatment is the bridge before the liver function restoration or liver transplantation treatment. In clinical studies, following treatment of chronic severe hepatitis B with plasma exchange plus hemofiltration, a survival rate of $48.3 \%$ was identified (13). For the patients in ICU with multi-organ dysfunction syndrome (MODS) and acute liver failure, the clinical study on the treatment of MODS coupled with plasma separation adsorption plus hemofiltration had a survival rate of $45.5 \%$ (14). The treatment of hepatic failure and multi-organ dysfunction comprehensive syndrome with plasma exchange plus CVVHDF showed a survival rate of $42.5 \%$ (15). According to the MODS scores, the liver score of the patients in the group was more than IV score, PTA $\leq 30 \%$. According to the staging in the hepatic failure diagnosis and treatment guideline, the patients belong to the middle and advanced hepatic failure, and three types of non-biological artificial liver treatment combinations were employed (16). Of 61 patients, there were 38 cases successfully rescued, with the survival rate of $62.3 \%$. In comparison to the above studies, the survival rate was significantly improved and the result was similar to the survival rate of $63.13 \%$ (17) in the treatment group in treatment of liver function failure with a variety of blood purification methods.

The rescue survival rate of the non-viral liver failure patient was $75.6 \%$, but the rescue survival rate of the virus liver failure patients was only $35.0 \%$ suggesting that the combined non-biological artificial liver technology played a clear role in improving the clinical prognosis. Different combinations of non-biological artificial liver combined treatment played a more significant role in improving the severe metabolic disorders when the liver cells were under severe damage and removing a great number of toxic substances and inflammatory mediators accumulated and also played a significant role in improving the clinical prognosis. For the patients with severe hepatic failure caused by non-viral failure, it played a significant role in reducing the mortality rate, probably because, compared with the hepatic failure due to viral hepatitis, the non-viral liver failure of the patients was easily increased. When the liver damage factors were terminated, after the damaged liver cells entered into the regeneration and repair stage after a period of 
damage, the liver function gradually recovered. The patients with viral liver failure in this group were mainly provided with treatment based on a past medical history of viral hepatitis for many years, when the incidence was acute liver failure, and the liver function was severely uncoupled. Thus, the mortality rate was very high and the results of that group also suggested that the efficacy of non-biological artificial liver was limited in the treatment of acute liver failure based on the chronic viral hepatitis, and the liver transplantation was the fundamental factor of the treatment (18).

By comparing the three combinations of non-biological artificial liver treatment methods, i.e., $\mathrm{PE}+\mathrm{HP}+\mathrm{CVVHDF}$, $\mathrm{PE}+\mathrm{CVVHDF}$ and HP+CVVHDF, before and after treatment, the HR, MAP, respiratory index $\left(\mathrm{PaO}_{2} / \mathrm{FiO}_{2}\right)$, TBIL and ALT were significantly improved $(\mathrm{P}<0.05)$. Specifically, TBIL and ALT in the PE+HP+CVVHDF and $\mathrm{PE}+\mathrm{CVVHDF}$ groups were decreased more significantly $(\mathrm{P}<0.01)$. After PT and ALB treatment, only the changes in the $\mathrm{PE}+\mathrm{HP}+\mathrm{CVVHDF}$ and $\mathrm{PE}+\mathrm{CVVHDF}$ groups were statistically different $(\mathrm{P}<0.05)$. The difference between TBIL decrease in the $\mathrm{PE}+\mathrm{HP}+\mathrm{CVVHDF}$ group and that in the HP+CVVHDF group was statistically significant, and the study results suggested that the $\mathrm{PE}+\mathrm{HP}+\mathrm{CVVHDF}$ combined method was more conducive to removing metabolites and poison and maintaining homeostasis. The plasma exchange can widely clear the endogenous toxins of the patients with liver failure such as endotoxin, bilirubin and bile acids. The macromolecules combined with the plasma protein and circulating immune complexes can simultaneously supplement the blood coagulation factor and improve coagulation function and supplement the serum ALB, conditioning factor, immunoglobulins and other biologically active substances, but because the toxins under the small and middle molecular weight are widely distributed to the tissue through the vessel wall, they cannot be cleared by only applying PE; thus, HP can mainly adsorb the cell toxic substances and aromatic amino acid as well as phenol, indole, short-chain fatty acids in the blood of the patients with liver failure. HA-type resin perfusion apparatus in the blood perfusion belongs to the neutral macroporous resin and can mainly adsorb the substance under the molecular weight of $500-5,000 \mathrm{kDa}$, and it can effectively absorb a variety of protein-bound toxins and cytotoxic substances inhibiting cell regeneration (19). CVVH can sustainably clear the molecules, ammonia and other toxic substances such as false neurotransmitters, free fatty acids, mercaptans, aromatic amino acids of the acute liver failure patients, increase CAMP content in cerebrospinal fluid, improve the brain energy metabolism, reduce and improve the hepatic encephalopathy (20). The CVVH can precisely control the capacity, sustainably and slowly remove the solutes and liquids, regulate the water and electrolyte acid-base balance and reduce the occurrence of acute liver failure cerebral edema.

In conclusion, the liver functions were improved to varying degrees after the three artificial liver treatment methods were applied, among which the efficacy of the PE+HP+CVVHDF method was more conducive to clearing the metabolites and toxins, especially clearing the bilirubin. After non-viral liver function failure treatment, the survival rate was significantly higher than that in the patients with viral liver failure.

\section{References}

1. McPhail MJW, Kriese S and Heneghan MA: Current management of acute liver failure. Curr Opin Gastroenterol 31: 209-214, 2015.

2. Stadlbauer V, Davies NA, Sen S and Jalan R: Artificial liver support systems in the management of complications of cirrhosis. Semin Liver Dis 28: 96-109, 2008.

3. Catalina-Rodríguez MV and Bañares-Cañizares R: Artificial liver support systems: update on albumin dialysis (MARS). Gastroenterol Hepatol 28: 453-460, 2005 (In Spanish).

4. Ting PP and Demetriou AA: Clinical experience with artificial liver support systems. Can J Gastroenterol 14 (Suppl D): 79D-84D, 2000.

5. Kjaergard LL, Liu J, Als-Nielsen B and Gluud C: Artificial and bioartificial support systems for acute and acute-on-chronic liver failure: a systematic review. JAMA 289: 217-222, 2003.

6. Liu J, Kjaergard LL, Als-Nielsen B and Gluud C: Artificial and bioartificial support systems for liver failure: a Cochrane Hepato-Biliary Group Protocol. Liver 22: 433-438, 2002.

7. Sadahiro T, Hirasawa H, Oda S, Shiga H, Nakanishi K, Kitamura $\mathrm{N}$ and Hirano T: Usefulness of plasma exchange plus continuous hemodiafiltration to reduce adverse effects associated with plasma exchange in patients with acute liver failure. Crit Care Med 29: 1386-1392, 2001.

8. Bektas M, Idilman R, Soykan I, Soydan E, Arat M, Cinar K, Coban S, Tuzun A, Bozkaya H, Ormeci N, et al: Adjuvant therapeutic plasma exchange in liver failure: assessments of clinical and laboratory parameters. J Clin Gastroenterol 42: 517-521, 2008.

9. Biancofiore G, Bindi LM, Urbani L, Catalano G, Mazzoni A, Scatena F, Mosca F and Filipponi F: Combined twice-daily plasma exchange and continuous veno-venous hemodiafiltration for bridging severe acute liver failure. Transplant Proc 35: 3011-3014, 2003.

10. Shi D: Advances in the treatment of acute liver failure. Chinese $J$ Critical Care Med 33: 92-94, 2013 (In Chinese).

11. Li M, Li J and Shi Z: Clinical research on the treatment of the patients with non-viral acute liver failure by different combinations of non-biologic artificial liver. Chinese J Emergency Med 23: 1198-1120, 2014 (In Chinese).

12. Komura T, Taniguchi T, Sakai Y, Yamashita T, Mizukoshi E, Noda T, Okajima M and Kaneko S: Efficacy of continuous plasma diafiltration therapy in critical patients with acute liver failure. J Gastroenterol Hepatol 29: 782-786, 2014.

13. Ye WJ, Li LJ, Yu HY, Zhang XP, Tian J and Bai MH: Clinical research of plasma exchange with continuous veno-venous hemofiltration in treating mid- and late-stage chronic severe viral hepatitis B patients. Chinese J Hepatol 13: 370-373, 2005 (In Chinese).

14. He CS, Shi W, Ye ZM, Liang XL, Zhang B, Liu SX and Qin TH: Efficacy and safety of coupled plasma filtration adsorption combined with continuous veno-venous hemofiltration for multiple organ dysfunction syndrome patients with acute liver failure. Chinese Critical Care Med 19: 47-49, 2007 (In Chinese).

15. Liu Y, He J, Che D and Yang W: The treatment of liver function failure and multi-organ dysfunction syndrome by artificial liver support system. Chinese Critical Care Medicine 8: 431-432, 2006 (In Chinese).

16. Hepatic failure diagnosis and treatment guideline. Chinese $\mathrm{J}$ Hepatol 14: 543-646, 2006.

17. Ye W, Jin J, Yu H and Wang J: Therapeutic effects of blood purification in 160 cases with liver failure. Chinese J Integrated Traditional and Western Medicine in Intensive and Critical Care 13: 370-372, 2006 (In Chinese).

18. Arjuna Singanayagam and William Bernal: Update on acute liver failure. Curr Opin Crit Care 21: 134-141, 2015.

19. Luo L, Yuan CL, Zeng WQ and Zhang DZ: Treatment of severe hepatitis by HA neutral macroporous resin hemoperfusion: an analysis of 40 cases. World Chinese J Digestol 16: 2533-2536, 2008 (In Chinese).

20. Slack AJ, Auzinger G, Willars C, Dew T, Musto R, Corsilli D, Sherwood R, Wendon JA and Bernal W: Ammonia clearance with haemofiltration in adults with liver disease. Liver Int 34: 42-48, 2014. 